
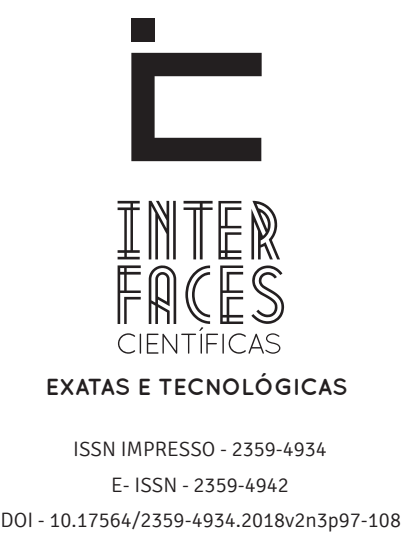

\title{
LEVANTAMENTO DO PERFIL DOS PROFISSIONAIS E DAS EMPRESAS DE TECNOLOGIA DA INFORMAÇÃO (TI) DA CIDADE DE ITABAIANA - SE
}

SURVEY OF THE PROFILE OF ITABAIANA CITY INFORMATION TECHNOLOGY PROFESSIONALS AND COMPANIES (IT) - SE

\section{LEVANTAMIENTO DEL PERFIL DE LOS PROFESIONALES Y DE LAS EMPRESAS DE TECNOLOGÍA DE LA INFORMACIÓN CTIJ DE LA} CIUDAD DE ITABAIANA - SE

Luciana Lourdys dos Santos Silva ${ }^{1}$ Rosimare da Silva Souza ${ }^{3}$

Levi da Costa Mota ${ }^{5}$
Francielly dos Santos ${ }^{2}$

Sidney Cassemiro do Nascimento ${ }^{4}$

\section{RESUMO}

A pesquisa foi realizada com o objetivo de tornar visível para a comunidade geral e acadêmica, o perfil dos profissionais e das empresas de tecnologia da informação (TI), existentes na cidade de Itabaiana (SE), formando uma base de conhecimento bastante útil para profissionais já atuantes na área, assim como pessoas que se interessam em entrar na área com melhor direcionamento. Além disso, o produto desta pesquisa permite às instituições de ensino da região identificarem os cursos que devem ser ofertados à comunidade para a formação adequada dos profissionais que as empresas esperam preencher suas vagas de emprego. Após a realização da pesquisa, foram analisados os dados obtidos, que permitiram traçar o perfil dos profissionais e das empresas de TI da referida cidade.

\section{PALAVRAS-CHAVE}

tecnologia da informação; mercado de trabalho; perfil dos profissionais; qualificação; competência. 


\section{ABSTRACT}

The research was carried out with the objective of making visible to the general and academic community the profile of the professionals and companies of information technology (IT), existing in the city of Itabaiana (SE), forming a very useful knowledge base for professionals already active in the area, as well as people who are interested in entering the area with better direction. In addition, the product of this research allows the educational institutions of the region to identify the courses that must be offered to the community for the ade- quate training of professionals that companies expect to fill their job vacancies. After the research was carried out, the data obtained were analyzed, which enabled the profile of the professionals and the IT companies of that city to be traced.

\section{KEYWORDS}

information technology; job market; profile of professionals; qualification; competence.

\section{RESUMEN}

La investigación fue realizada con el objetivo de hacer visible para la comunidad general y académica, el perfil de los profesionales y de las empresas de tecnología de la información (TI), existentes en la ciudad de Itabaiana (SE), formando una base de conocimiento bastante útil para profesionales ya actuantes en el área, así como personas que se interesan en entrar en el área con mejor dirección. Además, el producto de esta investigación permite a las instituciones de enseñanza de la región identificar los cursos que deben ser ofrecidos a la comunidad para la formación adecuada de los profesionales que las empresas esperan llenar sus vacantes de empleo. Después de la realización de la investigación, se analizaron los datos obtenidos, que permitieron trazar el perfil de los profesionales y de las empresas de TI de dicha ciudad.

\section{PALABRAS CLAVE}

tecnología de la información; mercado de trabajo; perfil de los profesionales; cualificación; competencia. 


\section{INTRODUÇ̃̃O}

$\mathrm{Na}$ atualidade estão ocorrendo várias transformações tecnológicas, fazendo com que as oportunidades para os profissionais de Tecnologia da Informação (TI) cresçam a cada dia que passa. 0 mercado de TI está sendo constantemente atualizado, gerando um mercado promissor e com altas possibilidades trabalhistas.

Segundo Shuster (2008), é definido e claro na atualidade 0 aumento das oportunidades para os profissionais da área de $\mathrm{Tl}$, onde cresce a demanda por vagas na área e consequentemente renumerações diferenciadas. Sendo a busca por essa área cada vez mais crescente, como também o aumento da demanda de profissionais, buscando se integrar nesse mercado cada vez mais propício.

Portanto, realizar uma pesquisa com essa dimensão possibilita refletir sobre as dificuldades que os profissionais enfrentam para integrar o mercado de trabalho, tais como dificuldades de qualificação, exigências enfrentadas na geração de novas vagas e obstáculos que muitas empresas enfrentam em encontrar profissionais com características necessárias que elas julguem essenciais para o cargo. Com isso é importante o estudo do perfil dos profissionais e das empresas de TI e suas exigências, tendo em vista que é um mercado amplo e em constante crescimento e que buscam mão de obra qualificada e que consiga acompanhar esse crescimento e demanda da área.

Assim, se faz necessário conhecer o perfil dos profissionais e das empresas de Tl existentes que atuam na cidade de Itabaiana-SE, permitindo com que os estudantes da área de TI ou qualquer pessoa que busca informações sobre esse mercado na cidade citada, faça uso dos dados fornecido neste trabalho.

0 presente trabalho se propõe a investigar as demandas que são exigidas pelo mercado de trabalho de TI da cidade de Itabaiana, tendo como campo de pesquisa as empresas que atuam nas áreas de: desenvolvimento de software, manutenção de hardware e provedora de internet.

Além de buscar identificar características dos profissionais requisitadas pelas empresas, formular um perfil ideal e apontar as características mais exigidas para inserção desses profissionais nas empresas, é importante destacar que a pesquisa buscou o ponto de vista dos responsáveis, ou seja, os gestores das empresas para o levantamento de informações sobre os perfis dos profissionais que elas desejam e quais deficiências muitos apresentam, como também o ponto de vista de seus respectivos profissionais.

$\mathrm{Na}$ procura para responder os objetivos do trabalho, foi realizada uma pesquisa quantitativa, com aplicação de questionários para gestores e empregados, tornando visível para a comunidade geral e acadêmica o perfil dos profissionais e das empresas de TI da cidade de Itabaiana, tentando facilitar a decisão de formação profissional, principalmente dos alunos que cursam informática.

Além disso, é também desejável conhecer as características que constroem o perfil dos profissionais, tais como: idade, cargo exercido, faixa salarial, nível de escolaridade, setor de atuação, conhecimento de idiomas, satisfação no cargo desempenhado, remuneração, oportunidades oferecidas pelas empresas, dentre outras. Formando, então, um conjunto de informações necessárias para análise do perfil do profissional.

Com base nos atributos dos profissionais houve a necessidade de levantar as características das empresas, envolvendo: ano de fundação, tamanho da empresa, áreas desenvolvidas, a maneira como é feita seleções na empresa, a frequência de novas vagas por ano, problemas enfrentados pelas empresas, o perfil de profissionais que elas requerem, se oferece apoio aos empregados, características necessárias para uma melhor formação de funcionários. Com a obtenção das respostas a estes questionamentos foi possível identificar o potencial e a deficiência tanto das empresas como dos profissionais de TI.

\section{FUNDAMENTAÇ̃̃O TEÓRICA}

Nesta seção, aborda-se o referencial teórico que sustenta o desenvolvimento do trabalho. Os temas abrangem a área de Tecnologia da Informação e o mercado de trabalho da área de TI. 


\subsection{TECNOLOGIA DA INFORMAÇÃO}

As aplicações para tecnologia da informação são vastas e interligadas a muitas áreas presentes em nosso cotidiano, dessa maneira não há possibilidades de conceito formado para o exposto assunto. Podemos notar que a Tl está sendo cada vez mais utilizada e cada vez mais presente no dia a dia das pessoas e empresas. A globalização, a expansão do capitalismo e as novas Tecnologias de Informação e Comunicação (TIC) têm gerado grandes mudanças sociais, políticas, econômicas e culturais, elevando a informação como um dos mais importantes recursos a ser utilizado na atualidade (SCHUSTER, 2008).

Segundo Meireles (2013, p. 419) Tl é um grupo de meios centralizados no armazenamento, processamento e comunicação de dados, ainda o modo pelo qual esses meios são estruturados em um composto habilitado para realizar um grupo de tarefas. Trata-se de um conceito muito abrangente, que integra outas aplicações como: 0 uso do software, do hardware, telecomunicações, sistema de informação, sistema da computação, unidos para o estabelecimento de uma organização com o alvo de fornecer dados e um conhecimento generalizado.

Para Schuster (2008), a definição de TI está relacionada com o desenvolvimento da tecnologia em uma determinada sociedade, onde a habilidade e a passagem de dados e conhecimento, com a reeducação da sociedade a nova fase tecnológica. Portanto, é evidente que estamos vivenciando uma sociedade da informação e na maioria das vezes não percebemos suas mudanças, suas atualizações e suas implicações que por sua vez atinge os princípios sociais, econômicos, interfere no modo de agir, pensar e organizar suas funções dentro da população.

Assim, a cada dia a tecnologia está infiltrando-se na sociedade, muitas vezes sem ser notada. Após essa suposta "infiltração" a sociedade tornou-se dependente da TI, sentindo a necessidade de obtê-la a cada instante.

\subsection{MERCADO DE TRABALHO DA ÁREA DE TI}

O constante desempenho do mercado de trabalho é de grande importância para a economia de um país ou de uma determinada região. Nele estão contidos os níveis de remuneração, as taxas de empregabilidade e investimentos. A sua definição não chega a ser restrita, ela depende das ofertas de vagas, das empresas e da busca constante por trabalho. As pessoas que estão em busca das supostas vagas, buscam valorizar suas qualificações, consequentemente, procuram também melhor a remuneração. Conclui-se que o mercado de trabalho é formado pela procura de atividade empregatícia e pelas empresas que ofertam essas atividades (BARTALOTTI; MENEZES, 2007).

0 mercado de trabalho atualmente caracteriza-se por buscar profissionais que precisam se aperfeiçoar nas transformações que o mercado sofre de acordo com a necessidade do país. Desse modo, o mercado de trabalho é de suma importância para o desenvolvimento da economia.

Existem vários fatores que são notórios dentro do mercado: níveis salariais, taxas de produção, taxas lucrativas, taxas de empregos/desemprego, capital desigual etc. $E$ todos eles são influenciados por setores políticos, econômicos e jurídicos (ARAÚJO; ALBUQUERQUE; SILVA, 2009). Esses fatores, são os pontos que mais evidenciam, atualizam e mobilizam o mercado de trabalho, assim como a economia.

Semelhante à implementação das novas tecnologias em muitos espaços da sociedade, visualiza-se um mercado diferenciado com preceitos próprios e com valores que englobam o profissional da informação e sua própria estratégia de trabalho. Assim, o mercado de trabalho de TI tem seus diferenciais dos demais, por exigir conhecimentos técnicos, experiências e práticas de trabalho que fazem com que esse mercado procure um profissional diferenciado dos outros (SCHUSTER, 2008).

A profunda implementação dos novos avanços tecnológicos, reforçou novas normas de padrões de qualidade e produtividade nas quais ocasionaram uma forte colisão no mercado de trabalho. É perceptível que cada vez mais as oportunidades para os profissionais que desejam ingressar nas áreas tecnológicas aumentam e com isso o mercado fica menos restrito, acompanhando o ritmo do crescimento (ALBANO; ZANATTA; GARCIA, 2013). 
No âmbito da economia e organização social, esse referido mercado vem se destacando, conforme avanços e experiência tecnológica vêm se diversificando, havendo então uma forte penetração dentro da sociedade, que se sente cada dia mais atraída pelo mercado de trabalho de TI. Dessa forma, a procura por empregos nas áreas da tecnologia da informação também aumenta, já que não deixa de ser um mercado tecnológico ultimamente cobiçado por diversos profissionais da área de TI.

Dessa forma, fica claro que o quadro em que o mercado de trabalho de TI se encontra está em crescimento, de acordo com as necessidades organizacionais de uma determinada sociedade, empregando valores e recursos que influenciam desde a política, a economia e as classes sociais seja ela qual for.

\subsection{QUALIFICAÇ̃̃O VS COMPETÊNCIA}

A constante atualização do mercado de trabalho, principalmente no mercado de tecnologia da informação, faz com que o profissional esteja sempre em busca de desenvolvimento e aprimoramento de sua formação profissional. A qualificação profissional está em contraste com a competência profissional, mas ao analisar ambos os conceitos se deduz que uma complementa a outra na formação profissional do trabalhador. Enquanto qualificação profissional está relacionada principalmente com habilidades e conhecimentos, a competência profissional está associada às atitudes.

A qualificação profissional, nada mais é que qualidades atribuídas a um indivíduo para que se instale de forma adequada ao mercado de trabalho, com o intuito de desenvolver atividades trabalhistas da melhor maneira possível (SIGNIFICADOS, 2011). Essa qualidade é uma tática básica para obter sucesso neste mundo globalizado e se tornou a essência que determina o futuro do profissional.

Para Schuster (2008), o conceito de qualificação está contido no progresso de novas técnicas de aprendizado adequadas ao setor profissional, à especialização por meio de cursos técnicos ou qualquer atividade que atribua um valor ao profissional, encaixando 0 mesmo ao mercado de trabalho.
Segundo Conceição e Arruda (2000), a qualificação refere-se ao salário, ao cargo exercido e também às tarefas executadas em determinada área de trabalho, como também às características de conhecimento do profissional.

A competência profissional nos dias atuais é um diferencial fundamental no momento de buscar uma oportunidade de trabalho. Em outras palavras, que esteja preparado de conhecimento, habilidades técnicas para atuar em diferentes funções (SIGNIFICADOS, 2011). Isso significa que competência é um talento onde o indivíduo consegue desenvolver suas tarefas de forma ágil. Essa característica diferenciada tem sido bastante disputada pelas empresas onde um funcionário competente consegue superar rapidamente os erros e obstáculos contidos nas empresas.

A competência na formação do profissional em um mercado de trabalho que está se atualizando acaba sendo um dos principais fatores na contratação do técnico. 0 mercado busca um profissional que tenha habilidades técnicas, experiência e características pessoais que sejam adotadas pelo trabalhador e beneficie a empresa na hora de tomar decisões em seu cargo.

Nesse ponto de vista, a definição de competência é uma junção de conhecimentos, atitudes e habilidades, ou seja, um conjunto de capacidades que um indivíduo pode realizar, as quais implicam em um ótimo desempenho. Desta forma, pode-se afirmar que competência nada mais é que uma juntura de todas as habilidades e recursos de um indivíduo habilitado a desenvolvê-las (FLEURY; FLEURY, 2001).

Segundo Deluiz (1996), a competência não se trata mais de o colaborador realizar tarefas na sua área de trabalho, mas sim da formação geral, formada por um conjunto de requisitos, envolvendo técnicas, conhecimento e habilidades.

\section{MATERIAIS E MÉTODO}

0 método de pesquisa usado neste artigo foi o da pesquisa exploratória. Segundo Lira (2014), é considerada como uma pesquisa de investigação 
ampla já que o assunto é pouco explorado, buscando então os esclarecimentos dos problemas criados. Sua finalidade é desenvolver, esclarecer e modificar conceitos e ideias, visando à formulação de problemas mais precisos para estudos posteriores.

Em relação aos procedimentos técnicos para coleta de informações, o trabalho baseia-se em pesquisa bibliográfica e pesquisa de campo. Na verificação dos contextos literários, pesquisaram-se artigos relacionados à tecnologia da informação, mercado de trabalho de TI e os perfis dos profissionais e das empresas de $\mathrm{Tl}$, buscando entender todos os seus conceitos, objetivos e finalidades.

Quanto a forma de a abordagem foi utilizada a pesquisa quantitativa, que visa levantar dados sobre um determinado grupo escolhido, com a aplicação de questionários para os funcionários e seus gestores que atuam nas empresas de TI segmentadas para a obtenção de dados primários. Os questionários continham questões relacionadas ao nível de escolaridade do profissional, sua faixa de remuneração, quantidade de idiomas, entre outras, já os questionários dos gestores abordava o porte da empresa, a forma de contratação, frequência que se realiza novos contratos e outras questões correlatas.

O campo de pesquisa foi de empresas da área de TI da cidade de Itabaiana-SE. O tempo destinado à aplicação e os resultados obtidos com o questionário foram de aproximadamente 15 dias úteis. A aplicação dos questionários foi realizada na última quinzena de setembro de 2016.

\section{RESULTADOS E DISCUSSÃO}

A seguir serão apresentados os resultados da pesquisa de campo realizada em nove empresas de TI na cidade de Itabaiana-SE, com um total de 18 funcionários participantes, representando amostra significativa das empresas de TI da cidade.

\subsection{QUESTIONÁRIOS DOS FUNCIONÁRIOS}

De acordo com os dados seguintes (FIGURA 1), verifica-se que, a maioria dos funcionários está na faixa etária de 21 a 24 anos (40,0\%), verifica-se ainda que de 25 a 29 anos (26,7\%) e 30 a 34 anos (26,7\%) a média foi semelhante e que já em pouquíssimas empresas de TI os funcionários têm idade de 35 a 45 anos (6,7\%).

Figura 1 - Idade dos funcionários das empresas de TI

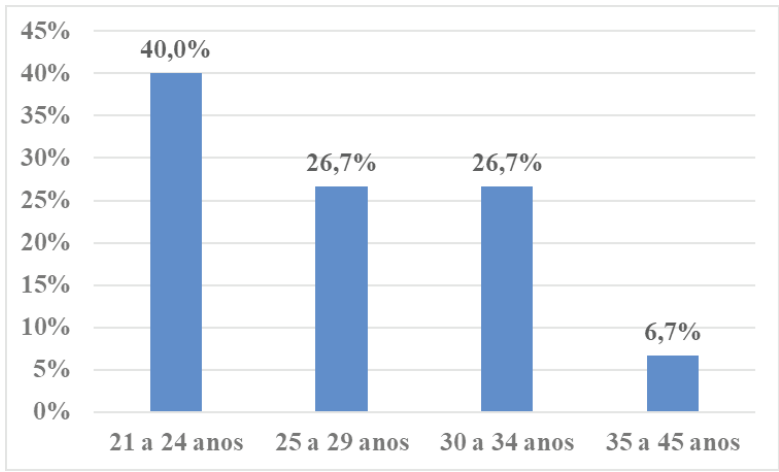

Fonte: Próprios autores (2016).

No gráfico da Figura 2, verifica-se que a maior parte dos funcionários das empresas é de técnicos de suporte ou técnicos de manutenção/hardware.

Figura 2 - Nível de formação dos funcionários na empresa de TI

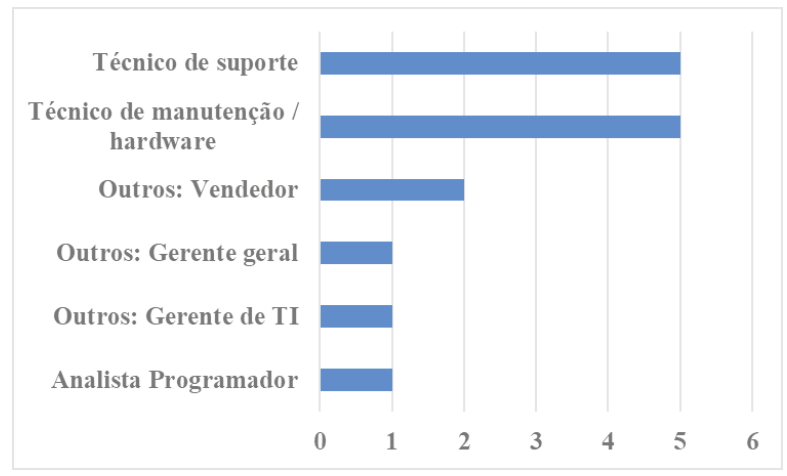

Fonte: Próprios autores (2016). 
Na Figura 3 pode ser vista a distribuição da faixa de renda dos funcionários entrevistado. Verifica-se que doze funcionários ganham em média até 2 salários mínimos pelo seu cargo atual na empresa, dois funcionários ganham de 2 a 3 salários mínimos e, apenas um funcionário ocupa cargo que paga de 5 a 8 salários mínimos.

Figura 3 - Faixa de renda dos funcionários das empresas

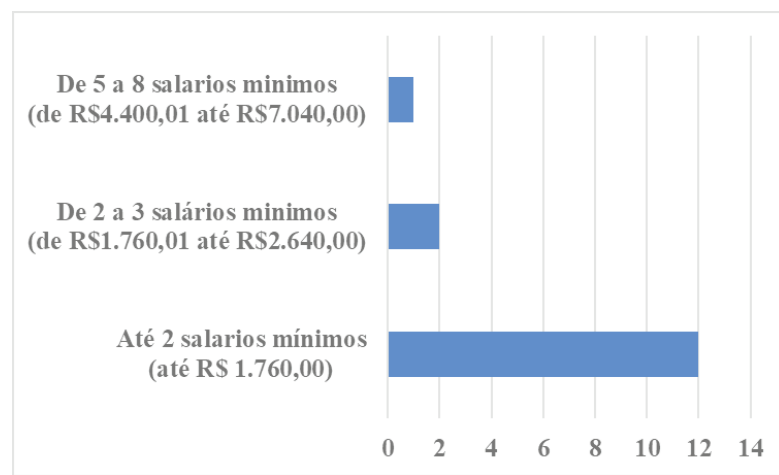

Fonte: Próprios autores (2016).

Os dados referentes à graduação dos funcionários são mostrados na Figura 4. Verifica-se que a maioria dos funcionários não possui graduação.

Figura 4 - Graduação dos funcionários das empresas de TI

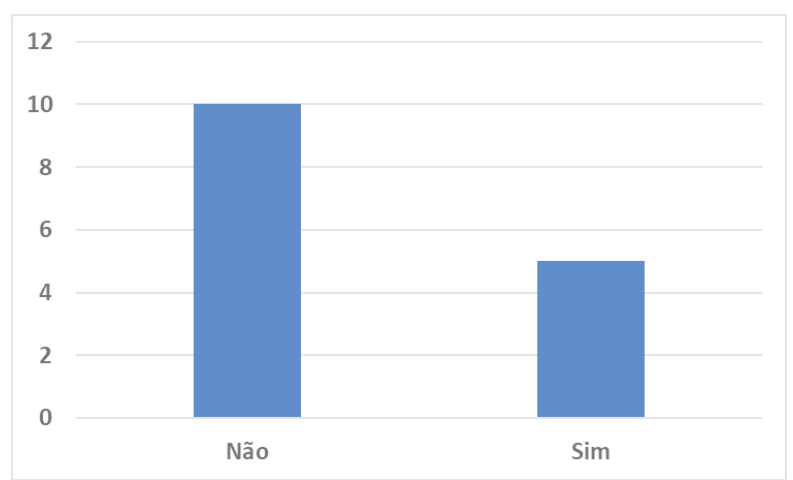

Fonte: Próprios autores (2016).

Na Figura 5 observa-se que o percentual de satisfação quanto ao cargo que ocupa na empresa foi bem elevado, de forma que $86,7 \%$ dos funcionários estão satisfeitos no cargo atual e 13,3\% não estão satisfeitos.

Figura 5 - Taxa de satisfação em relação ao cargo que ocupa na empresa

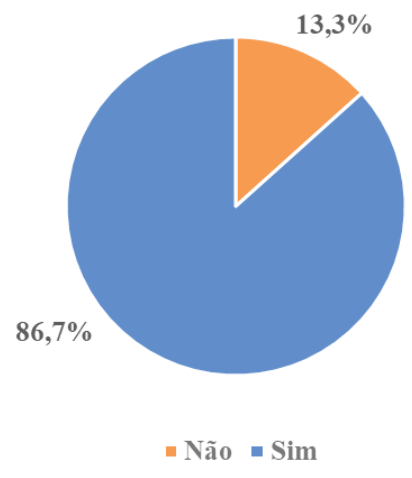

Fonte: Próprios autores (2016).

Logo em seguida, na Figura 6, verifica-se que a maior parte dos funcionários está satisfeita com sua remuneração. Dentre os entrevistados, $66,7 \%$ estão satisfeitos e $33,3 \%$ não estão satisfeitos com a remuneração atual.

Figura 6 - Taxa de satisfação com a remuneração

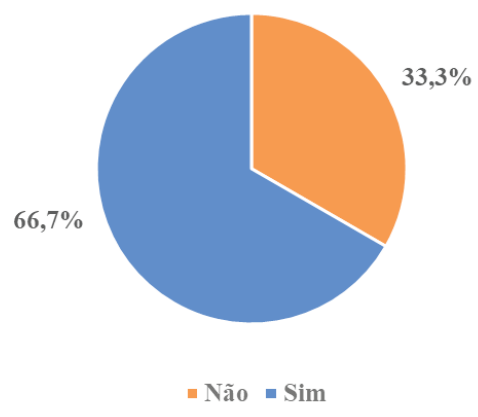

Fonte: Próprios autores (2016).

Conforme visto na Figura 7, apenas um funcionário entrevistado fala, tem o inglês no nível técnico, 
três funcionários falam inglês básico e a maioria não fala outros idiomas.

Figura 7 - Fluência dos funcionários em outros idiomas

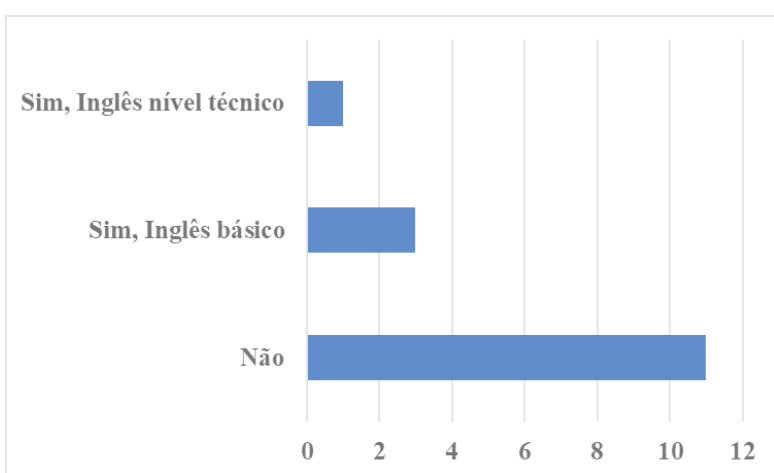

Fonte: Próprios autores (2016).

\subsection{QUESTIONÁRIOS DAS EMPRESAS}

Em relação ao tempo de fundação das empresas, pode-se observar por meio da Figura 8, que $50,0 \%$ das empresas têm em média de 5 a 10 anos de fundação, empresas acima de 10 anos de fundação são $33,3 \%$ do total, e $16,7 \%$ são empresas mais recentes, de até 4 anos existência.

Figura 8 - Tempo de fundação das empresas de TI

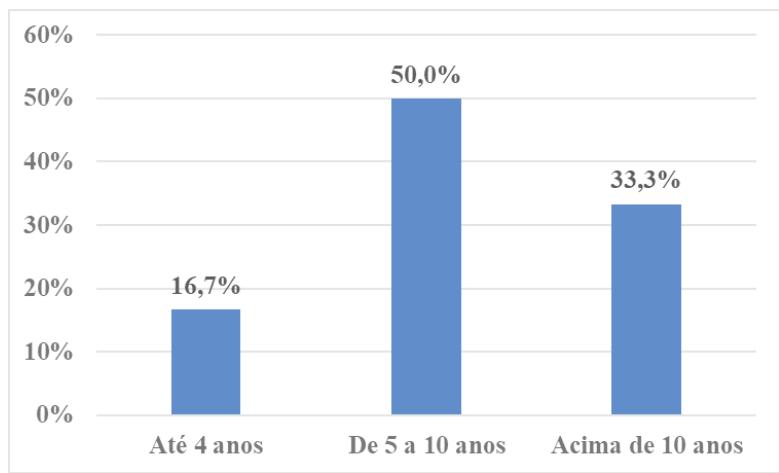

Fonte: Próprios autores (2016).

A Figura 9 mostra a distribuição das empresas em relação ao número de funcionários. Observa-se que cinco empresas entrevistadas são consideradas microempresas, pois têm de 1 a 9 funcionários de TI e apenas uma é considerada pequena empresa, tendo de 20 a 99 funcionários.

Figura 9 - Porte das empresas de TI

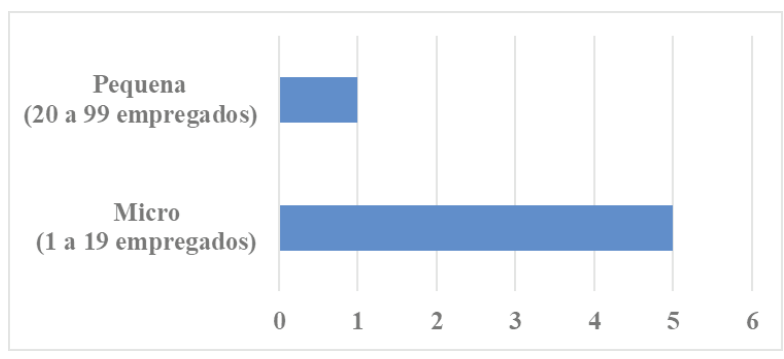

Fonte: Próprios autores (2016).

Com relação ao setor de atuação das empresas, a Figura 10 mostra que o setor de infraestrutura teve 3 empresas, o setor de desenvolvimento 2 empresas, o setor de soluções para internet 1 empresa e outros setores com 1 empresa.

A Figura 11 mostra a distribuição de cargos oferecidos pelas empresas entrevistadas. Nessa análise observa-se que o cargo de "técnico de manutenção/hardware" é o mais ofertado pelas empresas (5). Em seguida, estão juntos os cargos de "consultor de TI (vendas)", "programador", "técnico de suporte", "técnico de redes/telecomunicações" e "web designer" (4\%). Por último os cargos de "administrador de bancos de dados (DBA)", "administrador de redes", "analista de segurança de informações", "analista de sistemas", "analista de suporte", "analista de programador", "gerente de sistemas" e "webmaster" (3). 
Figura 10 - Setores de atuação das empresas de TI

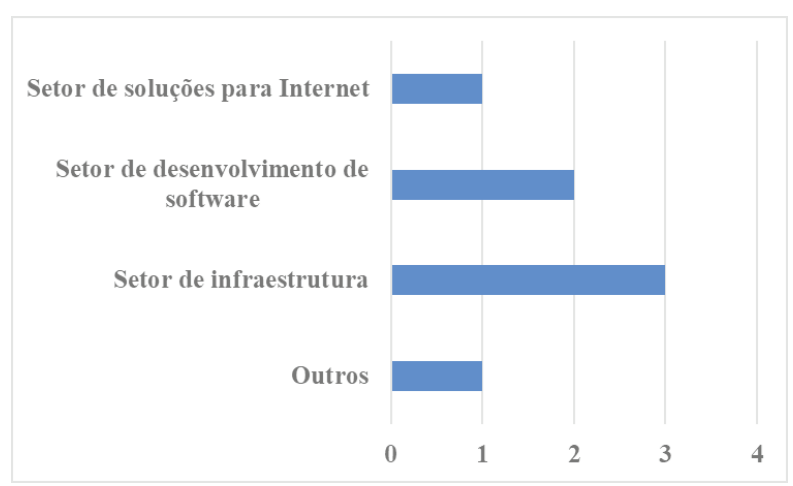

Fonte: Próprios autores (2016).

Figura 11 - Cargos de trabalho oferecidos pelas empresas

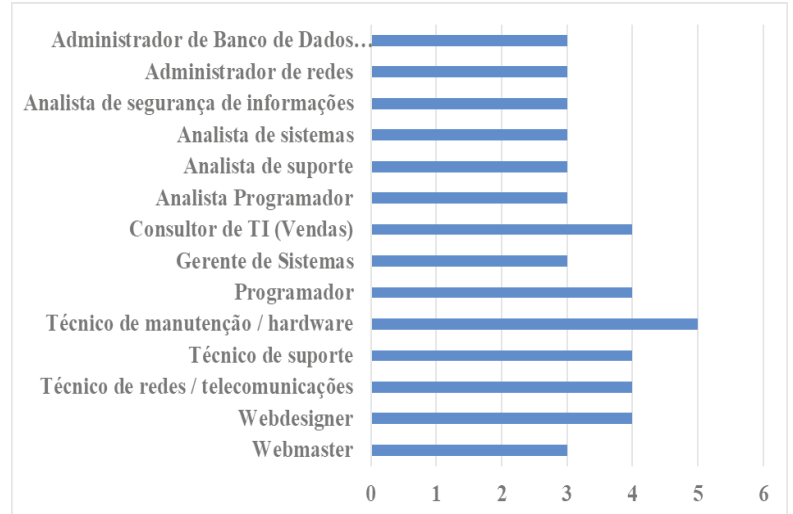

Fonte: Próprios autores (2016).

Na Figura 12 vê-se a distribuição das empresas em relação ao processo de seleção e verifica-se que a maior parte das empresas (6) seleciona seus funcionários por meio de entrevistas, sendo a indicação a segunda maior forma de seleção.
Figura 12 - Formas de seleção de funcionários

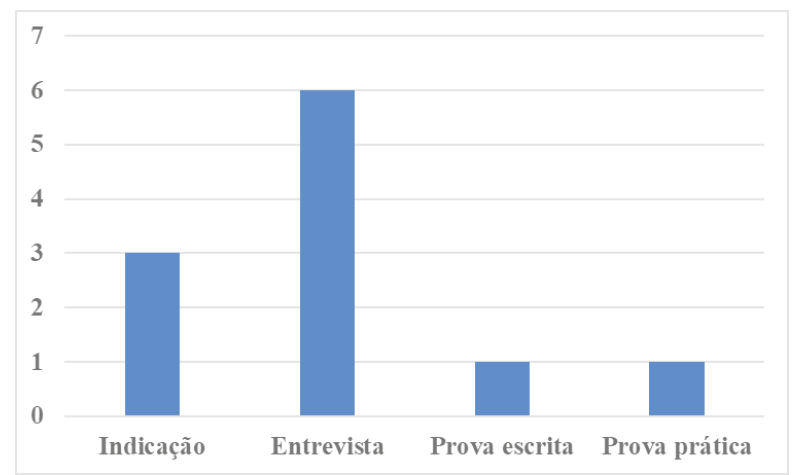

Fonte: Próprios autores (2016).

Figura 13 - Vagas de emprego disponibilizadas anualmente pelas empresas

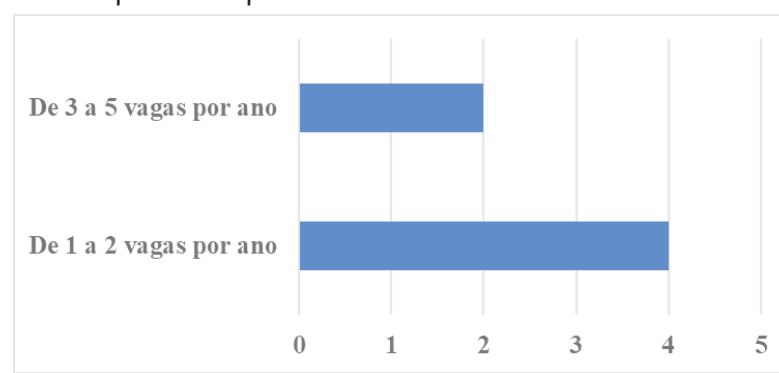

Fonte: Próprios autores (2016).

Em relação à frequência de vagas de emprego disponibilizadas pelas empresas, anualmente, pode-se observar por meio da Figura 13 que 4 empresas disponibilizam de 1 a 2 vagas por ano, sendo que 2 empresas disponibilizam de 3 a 4 vagas por ano.

Como mostra a Figura 14, verificou-se que o principal problema em uma seleção de novos profissionais foi a "falta de profissionais com qualificação/ competências". 
A Figura 15 mostra o resultado da pesquisa quanto às características dos funcionários que são valorizadas pelas empresas entrevistadas. Observa-se que a maior parte das empresas (5) valoriza profissionais de TI que têm competência e agilidade. Em seguida, empatados com 3 empresas cada, tem-se "capacidade técnica", a "honestidade", e a "proatividade". Por fim, com 1 empresa cada, a "habilidade para trabalhar em equipe" e o "relacionamento interpessoal".

Figura 14 - Dificuldades das empresas para realizar a seleção de profissionais

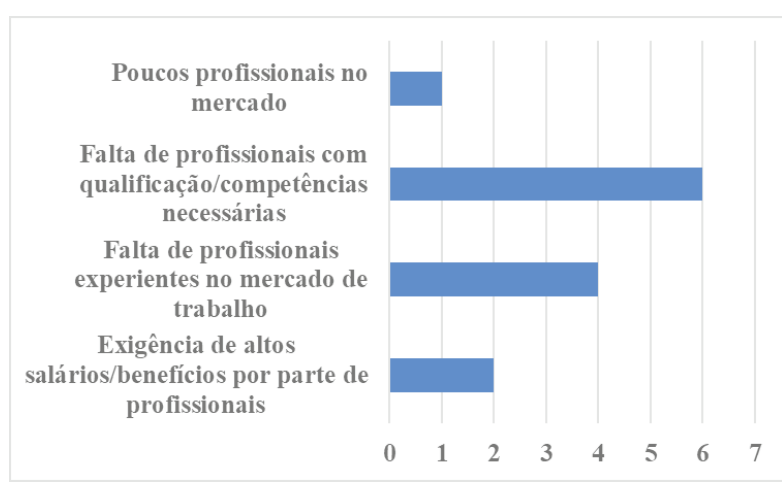

Fonte: Próprios autores (2016).

Figura 15 - Características dos profissionais de TI valorizadas pelas empresas

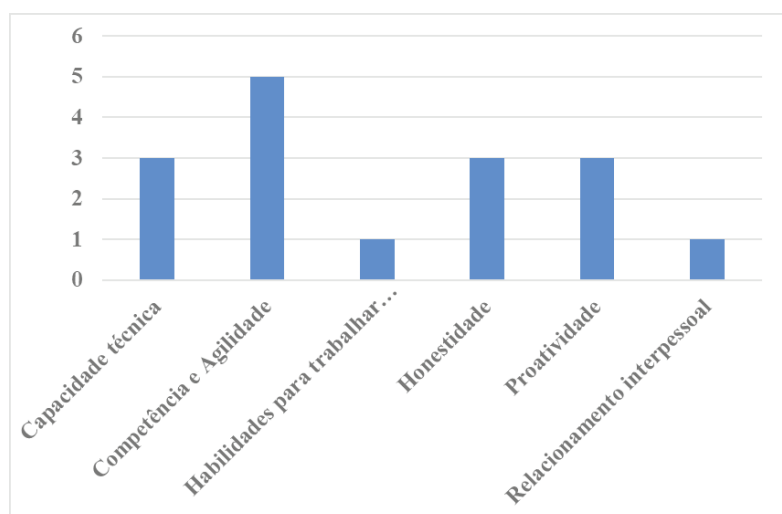

Fonte: Próprios autores (2016).

\section{CONSIDERACCÕES FINAIS}

No início do desenvolvimento deste artigo houve a necessidade de dividir suas atividades em duas etapas, onde sua primeira fase visou o aprimoramento da parte teórica, usando a pesquisa bibliográfica como instrumento de conhecimento, já a segunda fase foi destinada a coleta e análise de dados a partir dos questionários aplicados. Contudo algumas das atividades referentes ao segundo período foram realizadas na primeira etapa, para garantir um prazo maior para a realização das suas devidas tarefas.

$\mathrm{Na}$ aplicação dos questionários, segmentamos as empresas de $\mathrm{TI}$ conforme seu porte, ou seja, seu tamanho tanto em área como em funcionários dessa forma selecionamos empresas de: desenvolvimento de software, manutenção de hardware e provedora de internet. Após visitar, entregar e recolher os questionários, foi tabulado os dados em uma planilha eletrônica para a elaboração dos Gráficos que exibem os resultados deste trabalho.

Uma das principais dificuldades para a realização deste trabalho foi conseguir com que todas as empresas fornecessem os dados necessários no tempo previsto no cronograma. No total, nove empresas foram segmentadas, porém alguns dos seus gestores não entregaram como previsto. Apesar desses obstáculos foi possível obter uma amostra significativa.

Com execução desse tema, foi possível obter um amplo conhecimento sobre o perfil dos profissionais e das empresas da cidade de Itabaiana- SE, possibilitando, dessa forma, fomentar nas escolas de ensino médio da cidade citada, os resultados da pesquisa, elucidando e ajudando na decisão da formação profissional dos estudantes da região.

Este trabalho foi desenvolvido para atender a necessidade de conhecer os perfis dos profissionais e das empresas de TI da cidade de Itabaiana-SE, tornando visível as suas respectivas características. Acredita-se que esta pesquisa poderá ser de grande utilidade para as pessoas da área de tecnologia da informação (TI) como também para a comunidade geral e acadêmica. 


\section{REFERÊNCIAS}

ALBANO, Claudio Sonáglio; ZANATTA, Alexandre Lazaretti; GARCIA, Fabiane Tubino. Mercado de trabalho na área de Ti e a formação superior no Estado do Rio Grande do Sul. Revista Eletrônica de Sistemas de Informação, v.12, n.1, 2013. Disponível em: <http://www.periodicosibepes.org.br/index.php/ reinfo/article/view/1147>. Acesso em: 15 ago. 2016. ISSN 1677-3071 do: 10.5329/RESI

ARAÚJO, A.P.; ALBUQUERQUE, L.G.; SILVA, L.M.T. Mercado de trabalho e gestão de pessoas: mudanças e desafios. Capítulo 5. In: ALBUQUERQUE, L.G.; LEITE, N.P. (Org.). Gestão de pessoas - perspectivas estratégicas. São Paulo: Atlas, 2009.

BARTALOTTI, Otávio; MENEZES-FILHO, Naércio. A relação entre o desempenho da carreira no mercado de trabalho e a escolha profissional dos jovens. Economia Aplicada, v.11, n.4, p.487-505, 2007.

BRITO, Rodrigo. Definição-TI. Tecnologia da Informação. São Paulo, 2009.

Disponível em: <http://rodrigobritoti.blogspot.com. br/2009/06/ti-tecnologia-da-informacao.html>. Acesso em: 17 ago. 2016.

CONCEIÇÃO, Maria; ARRUDA, Calmon. Qualificação versus competência. 2000.

DA SILVA, Rafaela Alexandre; SILVA, Fernando Cesar Almeida; GOMES, Carlos Francisco Simões. Pesquisa sobre o perfil dos profissionais de TI do Rio de Janeiro. XXI Simpósio de Engenharia de Produção, Bauru-SP, 2014.

DELUIZ, Neise. A globalização econômica e os desafios à formação profissional. Boletim técnico do Senac, v.22, n.2, 1996. Disponível em: <http:// www.bts.senac.br/index.php/bts/article/view/500>. Acesso em: 18 ago. 2016.
FLEURY, Maria Tereza Leme; FLEURY, Afonso.

Construindo o conceito de competência.

Revista de administração contemporânea, v.5, n.SPE, 2001. Disponível em: <http://www. scielo.br/scielo.php?script=sci_arttext\&pid =S1415-65552001000500010 >. Acesso em: 19 ago. 2016.

LAURINDO, Fernando José Barbin et al. 0 papel da tecnologia da informação (TI) na estratégia das organizações. Gestão \& Produção, v.8, n.2, p.160-179, 2001. Disponível em: <http:// www.scielo.br/scielo.php?pid=S0104530X2001000200005\&script=sci_abstract\&tlng=pt>. Acesso em: 19 ago. 2016.

MEIRELLES, Fernando de Souza. Informática novas aplicações com microcomputadores. 2.ed. São Paulo: Makron Books, 2013.

SCHUSTER, Maria Elisa. Mercado de trabalho de tecnologia da informação: o perfil dos profissionais demandado. 2008. TCC (Graduação) - Instituto de Filosofia e Ciências Humanas, Universidade Federal do Rio Grande do Sul. Porto Alegre-RS, 2008.

\section{SIGNIFICADOS. Significados de qualificação} profissional. 2011. Disponível em: <http://www. significados.com.br/qualificacao-profissional/>. Acesso em: 17 ago. 2016.

SOUZA, Tatiele Pereira. Discurso e identidade: uma análise das publicações sobre trabalho, carreira e profissão no campo da tecnologia da informação. Áskesis, v.5, n.1, p.32, 2016.

ZANARDI, Francieli; SILVEIRA, Sidnei Renato. Perfil dos profissionais e das empresas de tecnologia da informação ( $\mathrm{TI})$ da Cidade de Frederico Westphalen-RS. 2014. TCC (Curso de Bacharelado em Sistemas de Informação) - Centro de Educação Superior Norte-RS, Universidade Federal de Santa Maria. Frederico Westphalen-RS, 2014. 
1 Egressa do Instituto Federal de Sergipe - Itabaiana-SE. E-mail: luciana_lourdys123@outlook.com

2 Egressa do Instituto Federal de Sergipe - Itabaiana-SE. E-mail: francinha_santos@outlook.com

3 Egressa do Instituto Federal de Sergipe - Itabaiana-SE. E-mail: rosesouza-sd17@outlook.com

4 Professor Efetivo no Instituto Federal de Educação, Ciência e Tecnologia de Sergipe (IFS), possui Mestrado em Ciência da Computação pela Universidade Federal de Sergipe (UFS). E-mail: sidneycn@gmail.com

5 Mestre em Ciências da Computação pela Universidade Federal de Sergipe (UFS)Especialista em Sistemas de Informação para Web pela Universidade Tiradentes (2003) e possui graduação em Processamento de Dados pela Universidade Tiradentes (1999). Professor do Instituto Federal de Aceito em: 19 de Outubro de 2017 